\title{
Coupled Effects of Polybrene and Calf Serum on the Efficiency of Retroviral Transduction and the Stability of Retroviral Vectors
}

\author{
STYLIANOS ANDREADIS ${ }^{1,3}$ and BERNHARD O. PALSSON ${ }^{2}$
}

\begin{abstract}
The relative concentrations of Polybrene (PB) and calf serum (CS) in retroviral supernatant have considerable effects on the efficiency of retrovirus-mediated gene transfer and the stability of retroviral vectors. The effect of PB on the efficiency of transduction of Moloney murine leukemia virus (MMuLV)-derived vectors is strongly dependent on CS. At a fixed CS concentration, the efficiency of transduction shows a maximum as a function of PB concentration. Increasing the CS concentration shifted this maximum to higher PB concentrations, but the value of the maximum remained the same. Therefore, there were optimal combinations of $P B$ and CS concentrations that maximized the efficiency of gene transfer: $4.4,8.8,13.2$, and $22 \mu \mathrm{g} / \mathrm{ml}$ of PB for $1 \%, 2.5 \%, 5 \%$, and $10 \%$ (vol/vol) CS, respectively. Moreover, the presence of PB affected significantly the kinetics of retroviral decay. The loss of retroviral activity did not follow simple exponential decay in the absence of PB during the decay period of the viral supernatant. The dynamics of viral inactivation showed an initial phase during which the transduction efficiency remained constant followed by exponential decay. However, in the presence of high $\mathrm{PB}$ concentrations $(13.2 \mu \mathrm{g} / \mathrm{ml})$ during the decay period of retroviral vectors, the initial delay was lost and the decay was exponential right from the outset. The present results suggest that in addition to virus-cell interactions that occur on the target cell surface, other physico-chemical processes may occur in solution that have a profound effect on retroviral activity and therefore they are of particular importance for gene therapy.
\end{abstract}

\section{OVERVIEW SUMMARY}

The effects of physico-chemical factors such as the polycation Polybrene (PB) and calf serum (CS) on the efficiency of gene transfer are investigated. PB and CS exhibit a coupled action, because the effect of one strongly depends on the concentration of the other. Optimal concentrations exist for which the efficiency of retroviral transduction is maximized. Retroviral decay exhibits sigmoidal kinetics in the presence of $\mathrm{PB}$, but exponential kinetics in the absence of PB from the viral supernatant, during the period of viral decay. These findings suggest that, in addition to virus-cell interactions that occur on the cell surface, physico-chemical processes may occur in solution that play an important role in retrovirus-mediated gene transfer.

\section{INTRODUCTION}

$\mathbf{G}$ ENE THERAPY HOLDS VAST POTENTIAL for the treatment of a wide variety of diseases, ranging from genetic diseases such as cystic fibrosis and adenosine deaminase deficiency, to cancer and AIDS (Anderson, 1992; Miller, 1992a; Crystal, 1995). Retroviruses are currently the vehicle of choice for the delivery of genes into mammalian cells for gene therapy applications (Hodgson, 1995). An inherent limitation that hampers the use of retroviral vectors* for gene transfer is their instability. The half-lives of moloney murine leukemia virus (MMuLV)-derived vectors in cell culture medium at $37^{\circ} \mathrm{C}$ have been measured by a number of investigators to be $5 \mathrm{hr}$ (Sanes et al., 1986), 3.5-6.5 hr (Paul et al., 1993), and 6-8 hr (Chuck, 1995). The mechanism by which MoMLV-derived vectors de-

${ }^{1}$ Department of Chemical Engineering, University of Michigan, Ann Arbor, MI, 48109-2136.

${ }^{2}$ Department of Bioengineering, University of California San Diego, La Jolla, CA, 92093-0412.

${ }^{3}$ Current address: Shriners Burns Institute, One Kendall Square, Cambridge, MA 02139.

*Throughout this communication we use the words viruses, retroviruses, retroviral particles and retroviral vectors interchangeably to denote replication incompetent retroviral vectors, as opposed to active viruses. 
cay is unknown. The mechanism of human immunodeficiency virus (HIV) inactivation has been proposed to be the shedding of glycoproteins from the lipid envelope of viral particles (Layne et al., 1992). Therefore, HIV loses its ability to bind to cellular receptors and consquently its infectivity is diminished. The short half-life of MMuLV-derived retroviral vectors has been shown to limit the distance that they travel before decaying and, therefore, retard significantly their ability to transfer genes successfully (Chuck and Palsson, 1996a). Understanding the factors that determine retroviral half-lives is of great significance for improving the reproducibility and efficiency of retrovirus-mediated gene transfer.

Many physico-chemical factors are known to influence the stability of retroviral vectors. The temperature at which retroviral vectors are produced has been reported to play a significant role in determining their half-lives because transduction is increased when the vectors are produced at $32^{\circ} \mathrm{C}$ as compared to $37^{\circ} \mathrm{C}$ (Kotani et al., 1994). Also, the temperature during the period of exposure of target cells to the virus has been shown to influence infectivity for many families of viruses such as retroviruses (Andersen and Nexo, 1983), herpes simplex (McClain and Fuller, 1994), sendai and influenza virus (Haywood and Boyer, 1982; Haywood, 1991), and baculovirus (Wickham et al., 1992).

In vivo studies have shown that retroviral vectors are inactivated by serum complement in an antiviral immune response (Hodgson, 1995). Polybrene (PB) is a polycation that is essential for retroviral transduction. $\mathrm{PB}$ is believed to promote the binding of viruses on the cell surface by neutralizing the electrostatic repulsion between the opposing bilayers (Coller, 1980; Coelen et al., 1983). Infectivity has been shown to increase with increasing PB concentration (Toyoshima and Vogt, 1969; Patt and Houck, 1985; Aubin et al., 1994; Chuck, 1995). However, at high concentrations and for long periods of exposure, toxic effects of PB on target cells have been observed (Toyoshima and Vogt, 1969).

The effect of PB and calf serum (CS) on the efficiency of transduction and retroviral stability was investigated in this study. Because PB is a positively charged polyelectrolyte and CS has many negatively charged proteins, an electrostatic interaction between these two factors is expected. This expectation motivated us to ask if the effect of PB on the efficiency of transduction depends on the levels of CS used during gene transfer. Furthermore, the direct effect of PB on the stability of retroviral particles was investigated. The question was, if the presence of $\mathrm{PB}$ in the viral supernatant affects the stability of retroviruses and the kinetic pattern of their decay, in addition to mediating virus-cell interactions during viral entry.

\section{MATERIALS AND METHODS}

\section{Cell culture}

Target NIH-3T3 fibroblast cells were seeded at 3,500 cells $/ \mathrm{cm}^{2}$ in either six-well plates (Costar, Cambridge, MA) or $10-\mathrm{cm}$ tissue culture dishes at least $24 \mathrm{hr}$ prior to exposure to retroviral supernatant. Cells were grown in Dulbecco's modified eagle's medium (DMEM) with $10 \%$ bovine calf serum supplement (GIBCO), unless otherwise specified, at $37^{\circ} \mathrm{C}$ and $5 \%$
$\mathrm{CO}_{2}$. The amphotropic retrovirus packaging cell line was kindly provided by Dr. J. Wilson, and was produced by transfecting the pMFG vector containing the LacZ gene under the MMuLV long terminal repeat (LTR) promoter, into ICRIP packaging cells (Danos and Mulligan, 1988). The packaging cell line was grown under the same conditions as the target cells.

\section{Retrovirus supernatant}

Packaging cells were grown nearly to confluence in DMEM with $10 \%$ calf serum supplement. Fresh medium was added to the cells $24 \mathrm{hr}$ before the virus supernatant was harvested and filtered through $0.45-\mu \mathrm{m}$ pore-sized filters (Gelman, Ann Arbor, MI). The filtered viral supernatant was immediately aliquotted and stored at $-80^{\circ} \mathrm{C}$ until use.

\section{Transduction}

Prior to exposure of cells to the viral supernatant, PB was added at concentration between $4.4-22 \mu \mathrm{g} / \mathrm{ml}$ (as indicated in each experiment) to promote viral entry into the target cells. The time of exposure of cells to the virus was $2 \mathrm{hr}$ (unless otherwise indicated). After the virus was removed, cells were washed twice with HBSS to remove any unbound virus, and fresh medium was added to the culture. Cells were allowed to grow for $48-72 \mathrm{hr}$ before the cultures were assayed for transduction efficiency.

\section{Flow cytometry}

FDG/PI Staining: The product of the transferred LacZ gene reacts with $\mathrm{d}-\beta$-D-galactopyranoside conjugated with fluoroisothiocyanate (FDG) to form a product readily detectable with flow cytometry. NIH-3T3 cells were prepared for flow cytometric analysis as follows. Each sample was washed twice with HBSS, and the cells were detached from the substrate with trypsin $(0.3 \mathrm{ml})$ and resuspended in fresh medium. Then the cells were centrifuged for $10 \mathrm{~min}$ at $1,000 \mathrm{rpm}$, resuspended in $20 \mu \mathrm{l}$ of medium, and placed in a water bath at $37^{\circ} \mathrm{C}$ for $5 \mathrm{~min}$. Immediately after, 70-100 $\mu 1$ of a hypotonic solution of $2 \mathrm{mM}$ FDG was added to each tube, and the tubes were placed in the water bath for $90 \mathrm{sec}$. Then the tubes were immediately placed on ice, and $500 \mu \mathrm{l}$ of cold $\left(4^{\circ} \mathrm{C}\right)$ phosphate-buffered saline (PBS) with $1 \%(\mathrm{wt} / \mathrm{vol})$ bovine serum albumin (BSA) and 30 $\mu \mathrm{g} / \mathrm{ml}$ of propidium iodide (PI) was added. Samples were left on ice and in the dark for at least $\mathbf{1 ~ h r}$ before they were filtered and processed for flow cytometry. Only viable cells (PI negative) were used to determine the fraction of transduced cells. Identification of $\mathrm{PI}^{-} / \mathrm{FDG}^{+}$cells was based on two control samples: one stained with FDG but without PI, and the other stained with PI but without FDG.

\section{Staining procedure for microscopic quantitation of
Lac $Z^{+}$cells}

The efficiency of transduction of 3T3 cells when very low viral titers were used was quantitated by counting the number of transduced (blue) cells under a microscope. The transduced cells turn blue when $\beta$-galactosidase ( $\beta$-Gal) (the product of the $\mathrm{Lac} Z$ gene transferred to cells by the virus) reacts with 5 -bromo4-chloro-3-indolyl- $\beta$-D-galactoside (X-Gal) (Sigma) to form a blue product. The staining procedure is as follows: Each well 
in a six-well plate was washed twice with $2 \mathrm{ml}$ of HBSS, and $1.5 \mathrm{ml}$ of fixation solution was added for $5 \mathrm{~min}$. Fixation solution consists of $2.1 \%$ (vol/vol) formaldehyde (Sigma) and $0.2 \%$ (vol/vol) glutaraldehyde (Sigma) in PBS. Following fixation, cells were washed twice with HBSS and staining solution was added. Staining solution was prepared as follows: immediately before staining, $50 \mu \mathrm{l}$ of $20 \mathrm{mg} / \mathrm{ml} \mathrm{X}$-Gal powder dissolved in $N, N$-dimethylformamide (DMF, Sigma), was added in $950 \mu \mathrm{l}$ (1/20 dilution) solution of $5 \mathrm{mM} \mathrm{K} \mathrm{K}_{3} \mathrm{Fe}(\mathrm{CN})_{6}$ (Sigma), $5 \mathrm{mM}$ $\mathrm{K}_{4} \mathrm{Fe}(\mathrm{CN})_{6} \cdot 3 \mathrm{H}_{2} \mathrm{O}$ and $2 \mathrm{mM} \mathrm{MgCl}_{2}$ (Sigma) in PBS. The samples were incubated for 3 days at $37^{\circ} \mathrm{C}$ to allow the blue color to develop in transduced cells, and the blue cells were counted. Cells that were not exposed to the vector but stained with $\mathrm{X}$ Gal served as a control.

For very low transduction efficiencies, on the order of 1-5\% of transduced cells, the sensitivity of flow cytometry decreases, because small differences on the order of 1 or $2 \%$ are the same order of magnitude as sample-to-sample variation and cannot be considered significant. Therefore, when low retroviral concentrations were used, the gene transfer efficiency was determined by microscopic counting of $\mathrm{LacZ}^{+}$(stained blue) cells, whereas for high retroviral concentrations flow cytometry was the method of choice.

\section{RESULTS}

The coupled effects of Polybrene and serum on the efficiency of retroviral transduction

Serum is needed for cell growth and metabolism. It has been shown for many cell lines, and in particular for fibroblasts

FIG. 1. Coupling of the effects of PB and CS on retrovirusmediated gene transfer. Vectors were propagated in $10 \%$ serum. To obtain a final concentration of $1 \%$ serum, we diluted the vector supernatant one-tenth with serum-free media. To obtain vector supernatant in $10 \%$ serum we diluted one-tenth with medium that contained $10 \%$ serum. Therefore, the vector concentration was one-tenth of the initial concentration of the supernatant harvested from the packaging cell lines, whereas the serum concentrations were different. Similarly, we obtained vector supernatants with $5 \%$ and $2.5 \%$ serum by changing the relative amounts of serum free medium and medium with $10 \%$ $\mathrm{CS}$ in which the vector supernatant was diluted one-tenth. Because the dilution ratio was the same, the vector concentration was maintained the same for all samples in each experiment. At the end of the period of exposure of cells to the vector, the cells were washed with HBSS and medium with $10 \%$ CS was added. Thus, the cells were exposed to medium with low serum concentration only for the period of exposure to the vector $(2 \mathrm{hr})$. A. Number of transduced cells as a function of PB concentration, for various CS concentrations. PB concentration of unity corresponds to $4.4 \mu \mathrm{g} / \mathrm{ml}$. B. Number of transduced cells as a function CS concentration for various PB concentrations. Identical results were obtained from three replicate experiments. All samples were in duplicate. The standard deviation is indicated by the size of the error bars. Transduction efficiencies were quantitated by microscopic counting of $\mathrm{X}$ Gal-stained, blue cells. All of the blue cells in each well were counted.
(Brooks 1976; Campisi et al., 1984; Larsson et al., 1985; Zetterberg and Larsson, 1985) that the serum content of the culture medium affects cell growth. Retroviruses can only infect growing celis (Springett et al., 1989; Miller et al., 1990) and integration of viral DNA depends on mitosis (Roe et al., 1993; Lewis and Emerman, 1994). The levels of CS in the culture medium of the target cells were changed to alter their growth rate and to study its effect on the efficiency of transduction. CS was found to have no effect on the rate of cell growth at concentrations of $1 \%, 2.5 \%, 5 \%$, and $10 \%$ (vol/vol) (data not shown). The CS concentration, however, affected the number of cells produced, presumably because at low CS concentrations serum-derived growth factors were depleted, thus limiting the maximum number of cells generated per culture.

Unexpectedly, the CS content of the medium affected retroviral transduction (Fig. 1). A series of experiments at different $\mathrm{CS}$ and $\mathrm{PB}$ concentrations revealed a strong coupling in the effect of these two concentrations on the efficiency of retroviral gene transfer. Specifically, the transduction efficiency showed
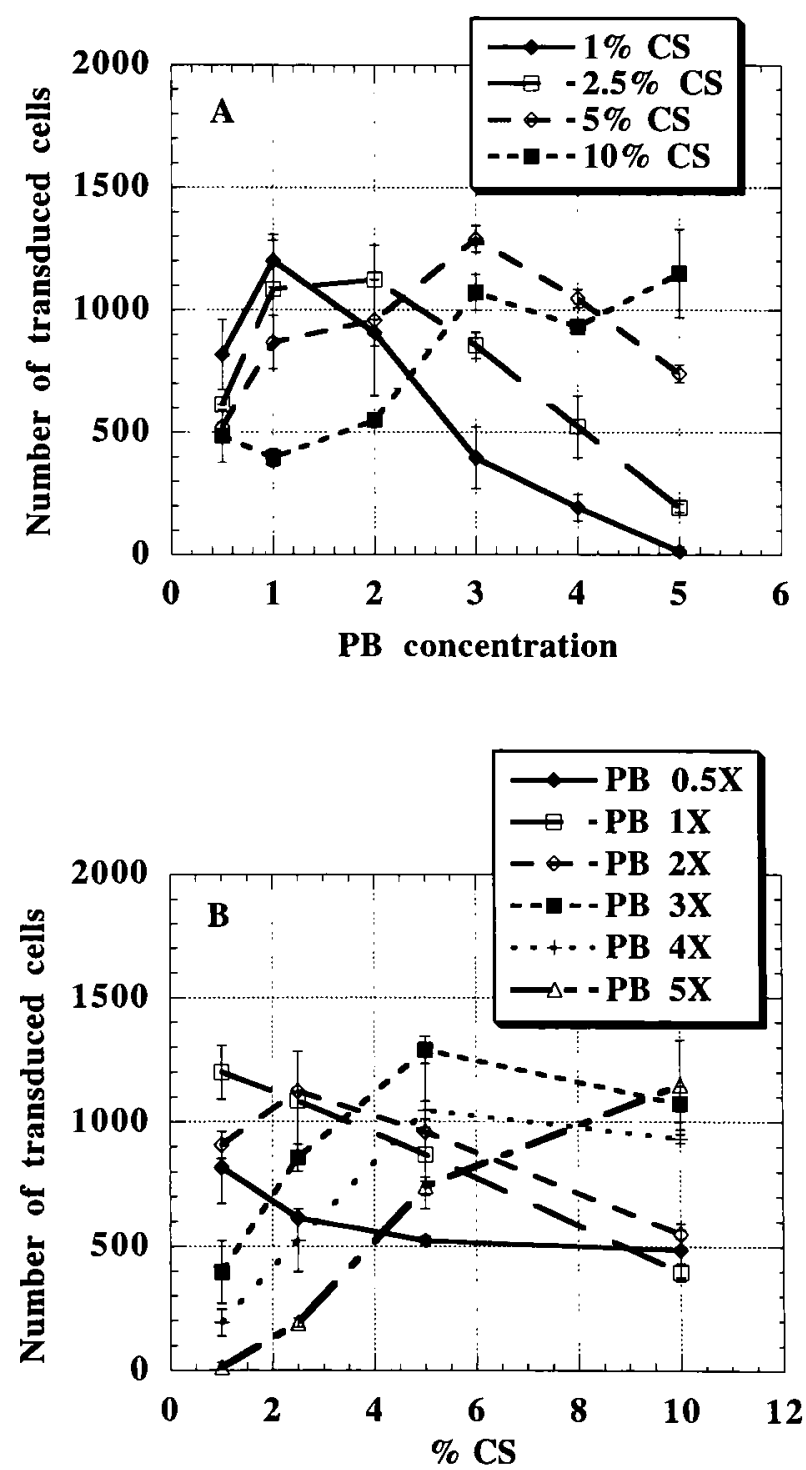
a maximum as a function of $\mathrm{PB}$ concentration at a fixed $\mathrm{CS}$ concentration. Changing the CS concentration shifted the location of this maximum but not its height. As the CS concentration increased the value of the maximum efficiency of transduction shifted to higher PB concentrations (Fig. 1A). Concentrations of PB higher than the optimal concentration resulted in decreased efficiencies of transduction. The same behavior was observed when the data were plotted as a function of CS content, for a fixed PB concentration (Fig. 1B). As the concentration of $\mathrm{PB}$ increased, the maximum efficiency of transduction shifted to higher $\mathrm{CS}$ concentrations. For very low PB concentrations $(2.2$ and $4.4 \mu \mathrm{g} / \mathrm{ml})$, the maximum was probably located at CS concentrations below $1 \%$, and is therefore out of the range used. These data showed a strong coupling between the actions of CS and PB, because the effectiveness of one depended on the concentration of the other. A three-dimensional representation of the data shows this interaction more clearly (Fig. 2). To investigate further the reasons for this coupling, experiments were performed to assess the direct effect of $\mathrm{CS}$ and PB on the stability of viral vectors.

\section{Retroviral inactivation follows sigmoidal dynamics}

The question that arose next was whether PB affects viral stability in solution in addition to mediating virus-cell interactions on the cell surface. A functional definition of stability was used in this study, that is, the decrease in the observable efficiency of transduction as a function of the time that viruses spent in solution before they enter a cell. Therefore, stability may refer to structural stability of the viral particle, or one of its components, or to some other mechanism that results in a decrease in the efficiency of transduction, as will be discussed below.

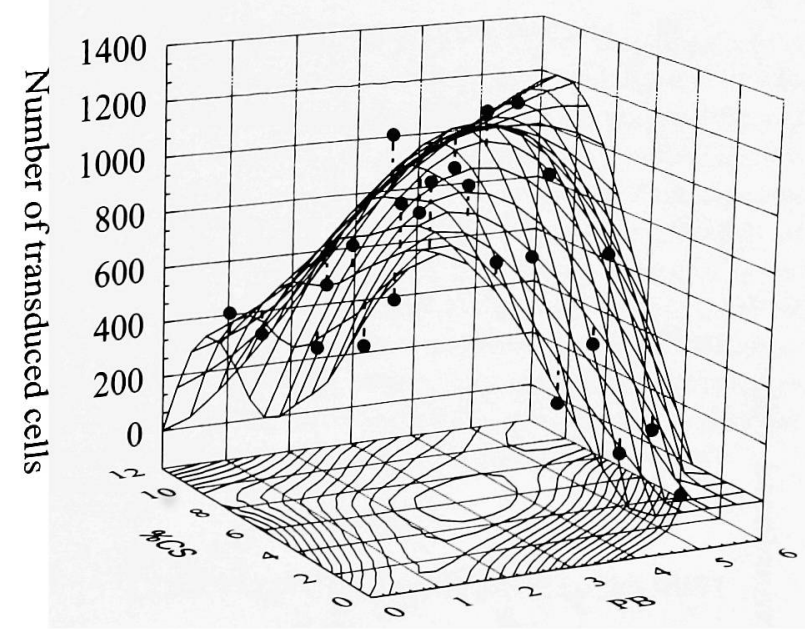

FIG. 2. Coupling of the effects of PB and CS on retrovirusmediated gene transfer. The data from Fig. 1, A and B, are summarized in this three-dimensional plot, which shows the number of transduced cells as a function of CS and PB concentrations simultaneously. The three-dimensional representation shows more clearly the strong interdependence of PB and $\mathrm{CS}$ concentrations. Observe that the same maximum transduction efficiency is attained by various PS CS concentration pairs.

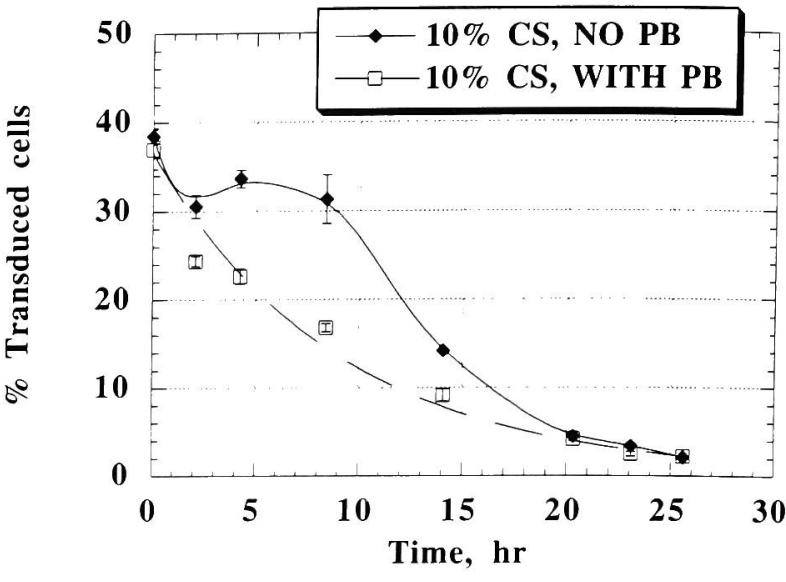

FIG. 3. Effect of PB on retroviral stability. The fraction of transduced cells is plotted as a function of the time of vector decay (prior to exposure of target cells to the vector). For each time point, two aliquots of retroviral supernatant were prepared. In one, the virus was incubated with $13.2 \mu \mathrm{g} / \mathrm{ml}$ PB during the decay period and the other with no PB. In the latter, PB was added to the viral supernatant at a final concentration of 13.2 $\mu \mathrm{g} / \mathrm{ml}$, just prior to exposure of cells to the vector. Therefore, exposure of target cells to the vectors always occurred in the presence of $13.2 \mu \mathrm{g} / \mathrm{ml}$ PB. All samples were in duplicate. The standard deviation is indicated by the size of the error bars. Transduction efficiencies were quantitated by fluorescence-activated cell sorting (FACS) analysis.

To answer the above question, experiments were performed to determine retroviral stability in the presence of $10 \% \mathrm{CS}$, with or without PB present in the viral supernatant during the decay period, before exposure of target cells to the vector. Viral supernatant was aliquotted in various tubes. There were two tubes for each time point, one for each PB concentration used (zero and $13.2 \mu \mathrm{g} / \mathrm{ml}$ of $\mathrm{PB}$ ). Then the tubes were placed in the incubator at $37^{\circ} \mathrm{C}$ for various times (decay periods of the retroviral vectors) when cells were exposed to the vector. PB was added to the tubes incubated without PB during the decay period, just prior to exposure of cells to the retrovirus, to a final concentration of $13.2 \mu \mathrm{g} / \mathrm{ml}$. Therefore, exposure of target cells to the vectors always occurred in the presence of 13.2 $\mu \mathrm{g} / \mathrm{ml} \mathrm{PB}$. At various times, $3 \mathrm{~T} 3$ target cells were exposed to viral supernatant for a period of $2 \mathrm{hr}$. After exposure to the virus, the cells were washed twice with HBSS, before fresh medium with $10 \%$ CS was added. The target cells were then allowed to grow for 48-72 hr before they were stained and analyzed for retroviral transduction by flow cytometry.

The presence of $\mathrm{PB}$ during the viral decay period caused (the time period to exposure of cells to the viral supernatant) a decrease in the stability of the vectors (Fig. 3). The data suggested a first-order viral decay with a half-life of $5.9 \pm 0.4 \mathrm{hr}$ (average of three experiments). In contrast, the stability of the viral vectors in the absence of $\mathrm{PB}$ during the decay period exhibited a behavior that is characteristic of a two-step inactivation process. For the first 4-5 hr, the transduction efficiency remained essentially constant, followed by an exponential decay with a half-life of $4.9 \pm 1.6 \mathrm{hr}$ (average of six experiments). Also, the viral activity in the presence of PB was lower at every 


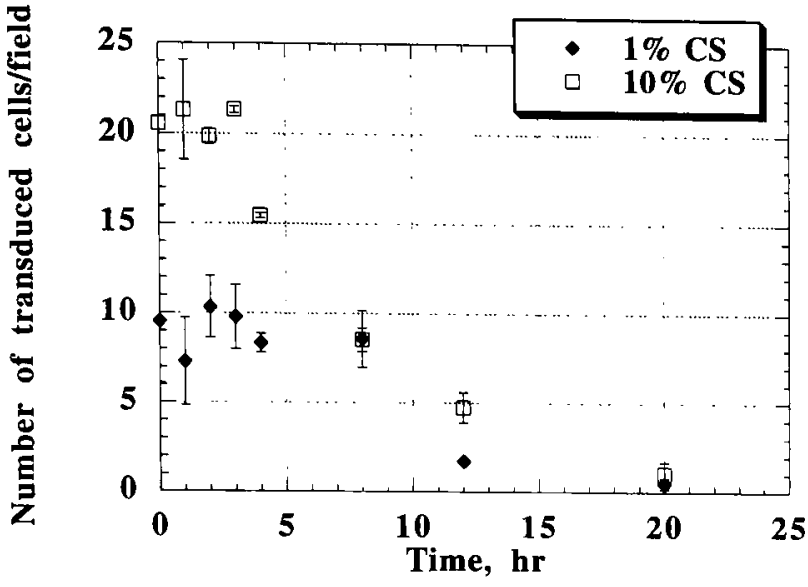

FIG. 4. Effects of PB and CS on retroviral stability. The number of transduced cells is plotted as a function of the time of vector decay (prior to exposure of target cells to the vector) for two CS concentrations, $1 \%$ and $10 \% \mathrm{vol} / \mathrm{vol}$. PB was added to the viral supernatant at a final concentration $13.2 \mu \mathrm{g} / \mathrm{ml}$ prior to exposure of cells to the virus, but not during the decay period. Transduction efficiencies were quantitated by microscopic counting of X-Gal-stained blue cells. In each well, blue cells were counted in 20 randomly chosen fields $(10 \times)$, and the average value per field was calculated. All samples were in duplicate. The standard deviation is indicated by the size of the error bars.

time point than in the absence of $\mathrm{PB}$ during the decay period (Fig. 3).

The same experiments were repeated for low viral titers (onetenth dilution of the harvested viral supernatant), and two CS concentrations ( $1 \%$ and $10 \% \mathrm{CS}$ ) to make sure that the slow inactivation phase was not due to high viral concentrations.
When the viral concentration is low, the transduction efficiency increases as a function of the initial retroviral concentration. However, for high viral concentrations, it reaches a plateau (Chuck, 1995; Andreadis and Paisson, 1996). Therefore, for very high viral titers, reduction of the number of viral particles due to viral decay would not result in decreased transduction efficiencies, until the number of retroviral particles was reduced to levels that corresponded to the linear region of the curves. The results of the experiments with low viral titers, for $1 \%$ and $10 \%$ (vol/vol) CS concentrations and no PB during the decay period, show an initial phase of slow inactivation of 4-5 hr, accompanied by a phase of exponential decay (Fig. 4). Therefore, these data suggest that the sigmoidal behavior of the dynamics of retroviral inactivation was not a result of high titers, but rather the effect of the presence of PB in the viral supernatant during the period of retroviral decay.

\section{DISCUSSION}

A major disadvantage of retroviral vectors as vehicles for gene delivery is their instability in solution and intracellularly (Kotani et al., 1994; Chuck, 1995; Hodgson, 1995; Andreadis and Palsson, 1996). This study presents results from experiments that examined the effects of PB and CS on the efficiency of retrovirus-mediated gene transfer and retroviral stability in the context of the functional definition of the term given above. $\mathrm{CS}$ and PB were found to affect the efficiency of transduction and the stability of retroviral vectors, and that the effects of the two are strongly interrelated (Fig. 2). In addition to mediating virus-cell interactions at the level of entry, the presence of $\mathrm{PB}$ in the viral supernatant during the decay period was found to affect the dynamics of viral inactivation in solution away from the cell monolayer.
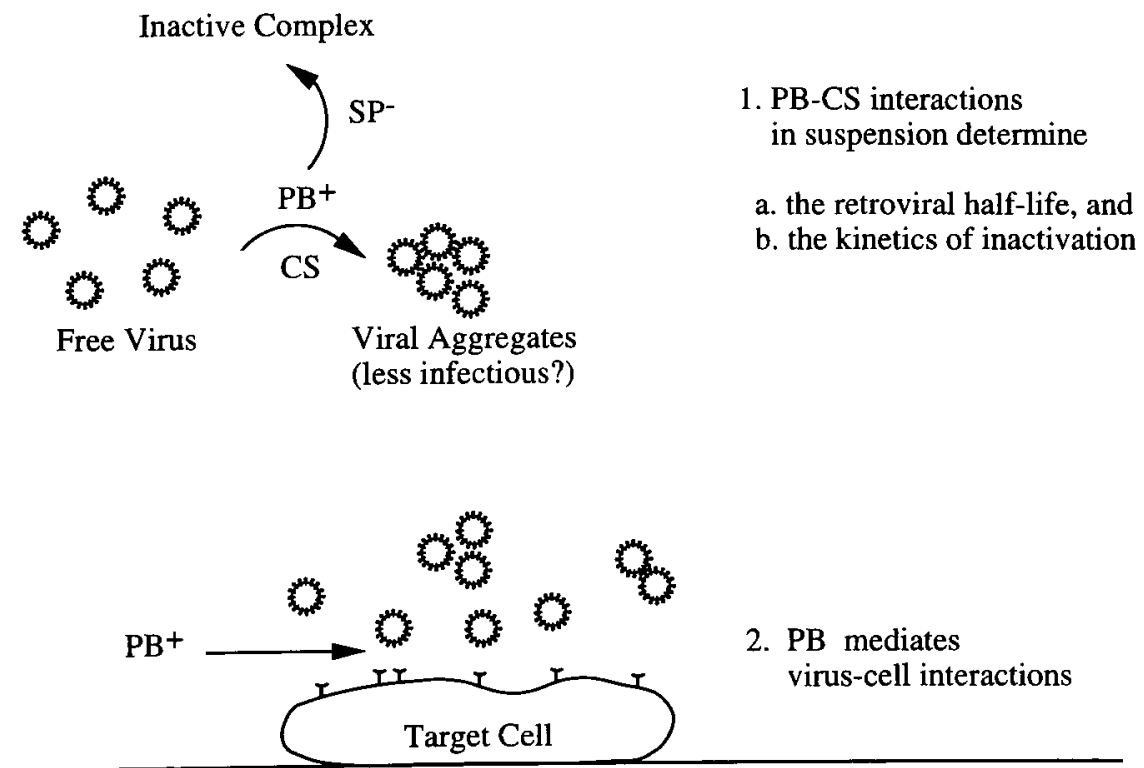

FIG. 5. Summary of the possible mechanisms that can explain the coupled actions of PB and CS on retroviral gene transfer. $\mathrm{PB}$ interactions with serum proteins, $\mathrm{SP}^{-}$, and viral particles in suspension are shown, in addition to the interactions of $\mathrm{PB}$ with the target cell monolayer during viral binding and entry into the cells. See text for details. 
CS and PB were found to influence the efficiency of transduction of NIH-3T3 cells by retroviral vectors in a coupled way. The efficiency of transduction plotted as a function of $\mathrm{PB}$ shows a maximum, that is, shifted toward higher $\mathrm{PB}$ concentrations as the level of CS in the medium of target cells increases (Fig. 1A). The same behavior is observed when the data are plotted as a function of CS concentration (Fig. 1B). The strong coupling in the actions of the two becomes particularly clear when a threedimensional representation of the data is considered (Fig. 2). Their coupled action may be explained by two possible mechanisms (Fig. 5): First, PB induced virus aggregation that also depends on CS concentration and results in loss of retroviral vectors in the form of viral aggregates. Viral aggregates may be less infectious than single viral particles. PB may act electrostatically to neutralize the negative charges of viral particles, thus increasing the rate of collisions and aggregate formation. Therefore, the viral titer is effectively reduced and consequently the efficiency of transduction decreases. The second possible mechanism is the neutralization of positively charged PB by negatively charged serum proteins, basically a titration effect. The latter results in reduction of the effective PB concentration and consequently reduction in the efficiency of retroviral transduction.

The second finding of this study is that the presence of PB during the decay period of retroviral vectors prior to exposure to the target cells changes the dynamic pattern of retroviral decay. When no PB is added to the viral supernatant with $10 \%$ CS during the decay period, the kinetics of retroviral decay show a sigmoidal decrease, whereas in the presence of PB the decrease is exponential. The action of PB may be dual (Fig. 5). $\mathrm{PB}$ increases transduction probably by neutralizing the negative changes on the surfaces of the opposing retroviral and celIular bilayers (Toyoshima and Vogt, 1969; Lalezari, 1987; Coller, 1980), but it may also contribute to virus aggregation thus reducing the effective concentration of retroviral vectors and leading to reduced transduction efficiencies. On the other hand, PB titration by serum proteins would reduce the effective concentration of $\mathrm{PB}$ and, therefore, the presence of $\mathrm{PB}$ in retroviral supernatant during the decay period would lead to a reduction in the transduction efficiency.

The present results regarding the sigmoidal pattern of retroviral decay are in agreement with the pattern of decay reported for HIV-1 (Layne et al., 1992). The authors attributed this dynamic behavior to the requirement for a critical number of bonds between viral particles and cells so that the two surfaces adhere. The critical number of bonds is a function of the strength of the repulsive electrostatic potential between the surfaces and association constant of the reaction of viral glycoproteins with the cell-surface receptors.

The proposed mechanism of Polybrene-induced virus aggregation is supported by previous studies in different biological systems. PB has been shown to induce platelet aggregation and decrease their electrophoretic mobility. More rapid agglutination occurred and larger aggregates were formed in the presence of normal plasma as compared to von Willebrand plasma (Coller, 1980). The presence of normal plasma and high concentrations of $\mathrm{PB}$ resulted in the development of much larger aggregates comparing to small-size aggregates in the absence of plasma (Coller, 1980). Also, serum proteins have been shown to affect the performance of manual hexadimethrine bromide (Polybrene) test by destabilizing antibody-dependent aggregation (Lalezari, 1987).

An alternative explanation of the present results is that a serum component causes inactivation of retroviral vectors, possibly by inducing shedding of the viral glycoproteins, or by binding to viral glycoproteins or retroviral receptors on the surface of the target cells, thus impairing the ability of retroviral vectors to bind to cell-surface receptors and internalize. This scenario would predict a sigmoidal pattern of decay of MMuLV according to the hypothesis for the requirement for a critical number of bonds between viral and cellular surfaces, as it is stated above. In vivo studies suggest that serum complement proteins cause retroviral inactivation in an antiviral immune response (Hodgson, 1995). Similarly, a component might also inactivate retroviral vectors in vitro or inhibit viral binding and entry by another unknown mechanism. Recently, chondroitin sulfate proteoglycan, a component of the medium conditioned by packaging cells, has been found to inhibit retroviral activity in vitro (Ledoux et al., 1996).

Our results demonstrate that physico-chemical factors play an important role in the efficiency of retrovirus-mediated gene transfer and the stability of retroviral vectors. Understanding some of the mechanisms involved in these phenomena may unravel new efficient and simple ways to increase the levels of retroviral transduction and establish optimal conditions for retroviral gene transfer. A limited number of studies support this statement (Kotani $e t$ $a l ., 1994)$ and call for increasing attention to these factors. Although PB is thought to increase retroviral transduction by mediating virus-cell interactions that occur on the cell surface, the present study suggests that other physico-chemical processes may occur in solution that affect the stability of retroviral vectors and, therefore, they are of importance for gene therapy. Because all clinical studies use protamine instead of $\mathrm{PB}$, similar studies with protamine should also be conducted. Studies with different polymeric electrolytes that increase transduction efficiencies could also provide insight into the mechanism of their action, which may be more complex than neutralization of electrostatic interactions between particles of opposite charge.

In summary, the effect of PB and CS on retroviral transduction and stability of retroviral vectors was investigated. We found that $\mathrm{PB}$ and $\mathrm{CS}$ affect the efficiency of transduction in a coupled way. Optimal concentrations of PB and CS exist for which gene transfer is maximized. Moreover, the presence of $\mathrm{PB}$ in the viral supernatant during retroviral decay affects the kinetics of decay of retroviral vectors. Two alternative mechanisms are proposed that may explain these data. PB induced virus aggregation, which reduces the effective concentration of retroviral particles. Alternatively, neutralization of the positively charged $\mathrm{PB}$ by negatively charged CS components could decrease the effective concentration of $\mathrm{PB}$. The present data argue for the importance of processes that may occur in solution and affect the stability of retroviral particles, in addition to the processes that occur on the cell surface, during the steps of viral binding and entry into the target cells.

\section{REFERENCES}

ANDERSEN, K., and NEXO, B. (1983). Entry of murine retroviruses into mouse fibroblasts. Virology 125, 85-98.

ANDERSON W. (1992). Human gene therapy. Science 256, 808-813. ANDREADIS, S., and PALSSON, B. (1996). Kinetics of retrovirusmediated gene transfer: the importance of intracellular half-life. J. Theoret. Biol. 182, 1-20. 
AUBIN, R., WEINFELD, M., MIRZAYANS, R., and PATERSON, M. (1994). Polybrene/DMSO-assisted gene transfer. Generating stable transfectants with nanogram amounts of DNA. Mol. Biotechnol. 1, $29-48$.

BROOKS, R. (1976). Regulation of fibroblast cell cycle by serum. Nature 260, 248-250.

BUNNELL, B., MUUL, L., DONAHUE, R., BLAESE, R., and MORGAN, R. (1995). High-efficiency retroviral-mediated gene transfer into human and nonhuman primate peripheral blood lymphocytes. Proc. Natl. Acad. Sci USA 92, 7739-7743.

CAMPISI, J., MORREO, G., and PARDEE, A. (1984). Kinetics of g1 transit following brief starvation for serum factors. Exp. Cell Res. $152,459-466$.

CHUCK, A., and PALSSON, B. (1996a). Consistent and high rates of gene transfer can be obtained using the flow through transduction over a wide range of retroviral titers. Hum. Gene Ther. 7, 743-750.

CHUCK, S. (1995). "Directed retroviral motion as a means of enhancing gene transfer for gene therapy." Ph.D. thesis, University of Michigan.

COELEN, R., JOSE, D., and MAY, J. (1983). The effect of hexadimethrine bromide (polybrene) on the infection of primate retroviruses SSV1/SSAV1 and BaEV. Arch. Virol. 75, 307-311.

COFFIN, J. (1990). Retroviridae and their replication. In Fundamental Virology. B.N. Fields and D.M. Knipe, eds. (Raven Press, New York, NY) pp. 645-708.

COFFIN, J. (1992). Structure and classification of retroviruses. In The Retroviridae. J.A. Levy, ed. (Plenum Press, New York, NY) pp. 19-49.

COLLER, B. (1980). Polybrene-induced platelet agglutination and reduction in electrophoretic mobility: enhancement by von Willebrand factor and inhibition by vancomycin. Blood 55, 276-281.

CRYSTAL, R. (1995). Transfer of genes to humans: early lessons and obstacles to success. Science 270, 404-410.

DANOS, O., and MULLIGAN, R. (1988). Safe and efficient generation of recombinant retroviruses with amphotropic and ecotropic host ranges. Proc. Natl. Acad. Sci. USA 85, 6460-6464.

HAYWOOD, A. (1991). Evidence for multiple steps in enveloped virus binding. In Cell and Model Membrane Interactions. S. Ohki, ed. (Plenum Press, New York, NY) pp. 337-374.

HAYWOOD, A., and BOYER, B. (1982). Sendai virus membrane fusion: Time course and effect of temperature, $\mathrm{pH}$, calcium and receptor concentration. Biochemistry 21, 6041-6046.

HODGSON, C. (1995). The vector void in gene therapy. Bio/Technology 13, 222-225.

KOTANI, H., NEWTON, P., III, ZHANG, S., CHIANG, Y., OTTO, E., WEAVER, L., BLAESE, R., ANDERSON, W., and MCGARRIRY, G. (1994). Improved methods of retroviral vector transduction and production for gene therapy. Hum. Gene Ther. 5, 19-28.

LALEZARI, P. (1987). The manual hexadimethrine bromide (polybrene) test. Effects of serum proteins and practical applications. Transfusion 27, 295-301.

LARSSON, O., ZETTERBERG, A., and ENGSTROM, W. (1985). Consequences of parental exposure to serum free medium for progeny cell division. J. Cell Sci. 75, 259-268.

LAYNE, S., SPOUGE, J., and DEMBO, M. (1989a). Analytic results for quantifying HIV infectivity. Bull. Math. Biol. 51, 715-730.

LAYNE, S., SPOUGE, J., and DEMBO, M. (1989b). Quantifying the infectivity of human immunodeficiency virus. Proc. Natl. Acad. Sci. USA 86, 4644-4648.

LAYNE, S., MERGES, M., DEMBO, M., SPOUGE, J., CONLEY, S., MOORE, J., RAINA, J., RENZ, H., GELDERBLOM, H., and NARA, P. (1992). Factors underlying spontaneous inactivation and susceptibility to neutralization of human immunodeficiency virus. Virology 189, 695-714.

LEDOUX, J.M., MORGAN, J.R., SNOW, R.G., and YARMUSH, M.L. (1996). Proteoglycans secreted by packaging cell lines inhibit retrovirus infection. J. Virol. 70, 6468-6473.

LEWIS, P.F., and EMERMAN, M. (1994). Passage through mitosis is required for oncoretroviruses but not for human immunodeficiency virus. J. Virol. 68, 510-516.

LUCIW, P., and LEUNG, N. (1992). Mechanisms of retroviral integration. In The Retroviridae. J.A. Levy, ed. (Plenum Press, New York, NY) pp. 159-298.

MCCLAIN, D., and FULLER, A. (1994). Cell-specific kinetics and efficiency of herpes simplex virus type 1 entry are determined by two distinct phases of attachment. Virology 198, 690-702.

MILLER, A. (1992a). Human gene therapy comes of age. Nature 357, $455-460$

MILLER, A. (1992b). Retroviral vectors. Curr. Top. Microbiol. Immunol. 158, 1-24.

MILLER, D., ADAM, M., and MILLER, A. (1990). Gene transfer by retrovirus vectors occurs only in cells that are actively replicating at the time of infection. Mol. Cell. Biol. 10, 4239-4242.

MULLIGAN, R. (1993). The basic science of gene therapy. Science 260, 926-932.

OVERBEEK, J. (1952). Kinetics of flocculation. In Colloid science. H.R. Kruyt, ed. (Elsevier Publishing Company, Amsterdam, The Netherlands) pp. 279-301.

PATT, L., and HOUCK, J. (1985). Opposing effects of the polycation hexadimethrine (polybrene) on normal and leukemic lymphocytes. Pharmacology 30, 109-114.

PAUL, R., MORRIS, D., HESS, B., DUNN, J., and OVERELL, R. (1993). Increased viral titer through concentration of viral harvests from retroviral packaging cell lines. Hum. Gene Ther. 4, 609-615.

ROE, T., REYNOLDS, T., YU, G., and BROWN, P. (1993). Integration of murine leukemia virus DNA depends on mitosis. EMBO J. 12, 2099-2108.

SANES, J., RUBENSTEIN, J., and NICOLAS, J. (1986). Use of a recombinant retrovirus to study post implantation cell lineage in mouse embryos. EMBO J. 5, 3133-3142.

SPRINGETT, G., MOEN, R., ANDERSON, S., BLAESE, R., and ANDERSON, W. (1989). Infection efficiency of T lymphocytes with amphotropic retroviral vectors is cell cycle dependent. J. Virol. 63, 3865-3869.

TOYOSHIMA, K., and VOGT, P. (1969). Enhancement and inhibition of avian sarcoma viruses by polycations and polyanions. Virology 38, $414-426$.

WEISS, R. (1984). Experimental biology and assay of retroviruses. In RNA Tumor Viruses. R.A. Weiss, N.M. Teich, H.E. Varmus, and J. Coffin, eds. (Cold Spring Harbor Laboratory, Cold Spring Harbor, NY) pp. 209-260.

WEISS, R., SOMMERFELT, M., MCCLURE, M., CLAPHAM, P., and WEBER, J. (1989). Retrovirus receptors on human cells. In Cell Biology of Virus Entry, Replication, and Pathogenesis. R.W. Compans, A. Helenius and M.B. Oldstone, eds. (Alan R. Liss, New York, NY) pp. 67-74.

WICKHAM, T., SHULER, M., HAMMER, D., GRANADOS, R., and WOOD, H. (1992). Equilibrium and kinetic analysis of Autographa californica nuclear polyedrosis virus attachment to different insect cell lines. J. Gen. Virol. 73, 3185-3194.

ZETTERBERG, A., and LARSSON, O. (1985). Kinetic analysis of regulatory events in G1 leading to proliferation or quiescence of Swiss 3 T3 cells. Proc. Natl. Acad. Sci. USA 82, 5365-5369.

Address reprint requests to: Prof. Bernhard Palsson 9500 Gilman Drive Department of Bioengineering University of California San Diego La Jolla, CA 92093-0412

Received for publication July 12, 1996; accepted after revision November 22, 1996. 


\section{This article has been cited by:}

1. Makoto Hirano, Shin Nakamura, Fusako Mitsunaga, Maki Okada, Keiko Shimuzu, Takahisa Imamura. 2002. Transfer of maternally administered fusogenic liposome-DNA complexes into monkey fetuses in a pregnancy model. The Journal of Gene Medicine 4:5, 560-566. [CrossRef]

2. Germana Rappa , Aurelio Lorico , Markus Hildinger, Øystein Fodstad , Christopher Baum . 2001. Novel Bicistronic Retroviral Vector Expressing $\gamma$-Glutamylcysteine Synthetase and the Multidrug Resistance Protein 1 (MRP1) Protects Cells from MRP1-Effluxed Drugs and Alkylating AgentsNovel Bicistronic Retroviral Vector Expressing $\gamma$-Glutamylcysteine Synthetase and the Multidrug Resistance Protein 1 (MRP1) Protects Cells from MRP1-Effluxed Drugs and Alkylating Agents. Human Gene Therapy 12:14, 1785-1796. [Abstract] [PDF] [PDF Plus]

3. U. Herrlinger, A. Jacobs, A. Quinones, C. Woiciechowsky, M. Sena-Esteves, N.G. Rainov, C. Fraefel , X.O. Breakefield . 2000. Helper Virus-Free Herpes Simplex Virus Type 1 Amplicon Vectors for Granulocyte-Macrophage Colony-Stimulating Factor-Enhanced Vaccination Therapy for Experimental GliomaHelper Virus-Free Herpes Simplex Virus Type 1 Amplicon Vectors for Granulocyte-Macrophage Colony-Stimulating Factor-Enhanced Vaccination Therapy for Experimental Glioma. Human Gene Therapy 11:10, 1429-1438. [Abstract] [PDF] [PDF Plus]

4. Marisa H. Zahler, Adil Irani, Harmeet Malhi, Anne T. Reutens, Chris Albanese, Boumediene Bouzahzah, David Joyce, Sanjeev Gupta, Richard G. Pestell. 2000. The application of a lentiviral vector for gene transfer in fetal human hepatocytes. The Journal of Gene Medicine 2:3, 186-193. [CrossRef]

5. Patrick A. Gerin, Moira G. Gilligan, Peter F. Searle, Mohamed Al-Rubeai . 1999. Improved Titers of Retroviral Vectors from the Human FLYRD18 Packaging Cell Line in Serum- and Protein-Free MediumImproved Titers of Retroviral Vectors from the Human FLYRD18 Packaging Cell Line in Serum- and Protein-Free Medium. Human Gene Therapy 10:12, 1965-1974. [Abstract] [PDF] [PDF Plus] 